\title{
Introduction to the Special Section on "The Role of Psychotherapy Research in Psychotherapy Training: Mutual Influences and Relations"
}

\author{
Francesco De Bei, ${ }^{1}$ Diego Rocco, ${ }^{2}$ Silvia Salcuni ${ }^{2}$ \\ ${ }^{1}$ Department of Dynamic and Clinical Psychology, "Sapienza" University of Rome; ${ }^{2}$ Department of Developmental and Social Psy- \\ chology, University of Padua, Italy
}

"The common factor of outcome expectations might be a mechanism through which the specific factor of psychotherapist competence exerts its influence on treatment outcome."

(Westra, Constantino, Arkowitz, and Dozois, 2011, p. 283)

The idea to conceive a Special Section about psychotherapy training stemmed from the reflections, definitions of critical points, and suggestions that each of us, in different situations (i.e., didactic, internship, supervision), institutions (both university and private specialization schools), and roles (trainers in the present, trainees in the past, and current psychotherapists and researchers in psy-

Correspondence: Francesco De Bei, Department of Dynamic and Clinical Psychology, "Sapienza" University of Rome, Piazzale Aldo Moro 5, 00185 Rome, Italy.

E-mail: fdebei@hotmail.com

Citation: de Bei, F., Rocco, D., \& Salcuni, S. (2019). Introduction to the Special Section on "The Role of Psychotherapy Research in Psychotherapy Training: Mutual Influences and Relations. Research in Psychotherapy: Psychopathology, Process and Outcome, 22(3), 323325. doi: $10.4081 /$ ripppo. 2019.438

Key words: Psychotherapy training; Therapist factor; Therapeutic success; Trainee formation.

Contributions: the authors contributed equally.

Conflict of interest: the authors declare no potential conflict of interest.

Funding: none.

Received for publication: 5 November 2019.

Accepted for publication: 6 November 2019.

This work is licensed under a Creative Commons Attribution NonCommercial 4.0 License (CC BY-NC 4.0).

${ }^{\circ}$ Copyright: the Author(s), 2019

Licensee PAGEPress, Italy

Research in Psychotherapy:

Psychopathology, Process and Outcome 2019; 22:323-325

doi:10.4081/ripppo.2019.438 chotherapy), have developed concerning the training in psychotherapy. The main question arose as follows: Which trainee factors play an important role in the therapeutic process, making it effective? Consequently, what should a psychotherapy training school address most?

Moreover, in the last decades, both clinical and developmental research (e.g., Beebe \& Lachmann, 2002; Siegel, 2012) has taught us to review our view of development, psychopathology, and, consequently, the concept of the mind itself. This change has had a radical impact also in psychotherapy research. The gradual integration of this new knowledge (from the observation of motherchild micro-interactions to the attachment theory; from the studies on trauma to neuroscience) in its theoretical (and empirical) fabric has radically changed the way of conceiving the mechanisms of change and the process of psychotherapy. However, in the midst of these theoretical radical transformations, the way psychotherapists are trained has remained mostly unchanged and unstudied.

In this complex scenario, a spontaneous and critical question arises: What should or should not be involved in providing comprehensive and effective training for psychotherapists? Miller, Hubble, and Duncan (2008), reflecting on trainees' and therapists' effectiveness, stated: «it is critical that we find answers to these questions. If being the best is a matter of birth, personal disposition, or chance, the phenomenon would hardly be worth further study. But should (therapists' and trainees') talents prove transferable, the implications for training, certification, and service delivery are nothing short of staggering》 (p. 16).

They also stressed the importance of empirically monitoring the therapists' development in relation to training programs and personal factors and experiences. Addressing this issue is very difficult, especially considering that nowadays, the study of psychotherapy process research still presents huge challenges, and it is not yet possible to develop a unified theory of all the components that play a role in it.

The "starting from the model" approach to training has received many criticisms, such as that expressed by Beutler (1995), according to whom: «academic training programs continue to follow procedures that suggest a belief in the "germ theory of education". That is, they operate 
on the assumption that exposure to psychotherapy, through supervision and class instruction, over a finite period of time, will result in competence and expertise» (p. 490).

On the other hand, in the last decades, psychotherapy process researchers have increasingly focused on therapist variables (including personality aspects, the individual biographical background, and career; e.g., Baldwin \& Imel, 2013; Beutler et al., 2004) and on the therapeutic relationship (e.g., Norcross \& Lambert, 2011). Results show that these relational factors play a preeminent role in influencing the psychotherapy outcome, to the point where some authors (e.g., Wampold \& Imel, 2015) claimed that therapeutic techniques seem to play only a subordinate role in therapeutic success. As a result, the role of these variables is emphasized, and practitioners are encouraged to concentrate on the creation and cultivation of the therapy relationship, to assess the relational behaviors (e.g., therapeutic alliance, empathy), and to adapt or tailor the psychotherapy to the specific client.

This emphasis on relational factors appears to be, at least in part, in contrast with the emphasis that the training programs put on the specific treatment model. Accordingly, the training programs should have a place in the development of these relational and personal factors and develop criteria for assessing the adequacy of training in evidence-based therapy relationships and responsiveness (Norcross \& Lambert, 2018). From this perspective, research on the psychotherapy process could have a useful role in training programs because it focuses on the fundamental role played by relational factors in contributing to the formation of a psychotherapist.

On the basis of all these considerations, the wider scope of our Special Section was to bring these two perspectives, the research psychotherapy process and the training on psychotherapy, into dialogue. More specifically, the first focus was on contributions devoted to analyzing what space psychotherapy research has found in educational institutions. Our interest was, in particular, to collect contributions concerning the use of psychotherapy research data, methodologies, and the operationalized vision of clinical constructs to be able to make them the object of teaching within the training programs. In other words, can research, not only as data but as a methodological approach, find its place in training programs? If so, how?

Within the second focus, we wanted to collect research contributions that have deepened the characteristics of the psychotherapy training process, for example by defining the following: What are the factors involved? What are the relationships among the factors? What are their characteristics?

This Special Section is composed of three works that deepen, from different perspectives, the theoretical aspects underlying the relationship between research and training in psychotherapy, and four works that explore, by means of research, these aspects. Specifically, in his work,
Di Nuovo (2019) deepened the epistemological premises necessary to define psychotherapy as a science and, subsequently, which aspects of psychotherapy research should be considered in connecting within the training program, science, and practice to foster scientific attitudes in psychotherapists during their training.

Gennaro, Kleinbub, Mannarini, Salvatore, and Palmieri (2019) explored how the recent research data (embodiment-based research) on the role played by synchrony and attunement ability in an interpersonal relationship can be introduced in psychotherapy training. The authors proposed detailed steps to foster the dialogue between these domains.

In their article, Negri, Andreoli, Belotti, Barazzetti, and Hale (2019) analyzed, by means of a survey, the epistemology underlying the clinical and the research practice in trainees. The authors presented the results and, accordingly, proposed their point of view in optimizing the training opportunities.

The focus of the article by Talia, Taubner, and MillerBottome (2019) was on the attachment theory and on the way in which the recent advances in attachment-informed psychotherapy research can be used for practical guidance in psychotherapy training. The authors described in detail the implications of their point of view on both teaching and supervision activities.

Rocco, Gennaro, Filugelli, Squarcina, and Antonelli (2019) created an ad hoc questionnaire to detect which are - from the point of view of trainers, trainees, and psychotherapists - the factors believed to be important in psychotherapy training. Among the obtained factors, there seemed to be a particular interest in the "trainer's relational characteristics," which underlines how, as well as in the psychotherapy process, the relational factors have the main importance in training activities.

Messina, Gullo, Gelo, Giordano, and Salcuni (2019) presented the state of the art of the Italian contribution to the Interest Section on Therapist Training of the International Society for Psychotherapy Research (SPRISTAD), a specific section of the Society for Psychotherapy Research that confirms the attention that the theme debated in this Special Section receives in our scientific community.

Finally, Evers, Schröder-Pfeifer, Möller, and Taubner (2019), in their research, studied a specific aspect emerging during psychotherapy training, the Work Involvement, analyzed in its manifestations (healing and stressful involvement), and searching for their possible predictors. The authors analyzed the role of different predictors, distinguishing between the healing versus stressful involvement, and deeply discussed the implications in training activities.

As editors, our hope and expectation was to shed light on "training in psychotherapy" as a factor that influences the effectiveness and efficacy of psychotherapy outcome and process, standing at a complex crossing point between training programs, psychotherapy practice, and psy- 
chotherapy research. We would like to thank all the authors - and the reviewers - involved in this topic, who gave further cues to address the empirical definition of the factors involved in the complex challenge that training in psychotherapy as a transformative aspect represents.

\section{References}

Baldwin, S. A., \& Imel, Z. E. (2013). Therapist effects. In M. J. Lambert (Ed.), Bergin and Garfield's handbook of psychotherapy and behavior change (6th ed., pp. 258-297). New York, NY: Wiley.

Beebe, B., \& Lachmann, F. M. (2002). Infant research and adult treatment: Co-constructing interactions. Hillsdale, NJ: Analytic Press.

Beutler, L. E. (1995). The germ theory myth and the myth of outcome homogeneity. Psychotherapy: Theory, Research, Practice, Training, 32(3), 489-494. doi:10.1037/00333204.32.3.489

Beutler, L. E., Malik, M., Alimohamend, S., Harwood, T. M., Talebi, H., Noble, S., et al. (2004). Therapist variables. In M. J. Lambert (Ed.), Bergin and Garfield's handbook of psychotherapy and behavior change (Vol. 5). New York, NY: Wiley.

Di Nuovo, S. (2019). What research for what training in psychotherapy? Some methodological issues and a proposal. Research in Psychotherapy: Psychopathology, Process and Outcome, 22(3), 326-332. doi:10.4081/ripppo.2019.410

Evers, O., Schröder-Pfeifer, P, Möller, H., \& Taubner, (2019). How do personal and professional characteristics influence the development of psychotherapists in training? Results from a longitudinal study. Research in Psychotherapy: Psychopathology, Process and Outcome, 22(3), 389-401. doi:10.4081/ripppo.2019.424.

Gennaro, A., Kleinbub, J. R., Mannarini, S., Salvatore, S., \& Palmieri, A. (2019). Training in psychotherapy: a call for embodied and psychophysiological approaches. Research in Psychotherapy: Psychopathology, Process and Outcome, 22(3), 333-343. doi:10.4081/ripppo.2019.395
Messina, I., Gullo, S., Gelo, O. G., Giordano, C., \& Salcuni, S. (2019). An overview of the Italian contribution to the international multisite SPRISTAD study on psychotherapy training. Research in Psychotherapy: Psychopathology, Process and Outcome, 22(3), 379-388. doi:10.4081/ripppo.2019.418

Miller, S. D., Hubble, M., \& Duncan, B. (2008). Supershrinks: What is the secret of their success? Psychotherapy in Australia, 14(4), 14-22.

Negri, A., Andreoli, G., Belotti, L., Barazzetti, A., \& Martin, H. (2019). Psychotherapy trainees' epistemological assumptions influencing research-practice integration. Research in Psychotherapy: Psychopathology, Process and Outcome, 22(3), 344-358. doi:10.4081/ripppo.2019.397.

Norcross, J. C., \& Lambert, M. J. (2011). Psychotherapy relationships that work. Psychotherapy, 48(1), 4-8. doi:10.1037/ a0022180

Norcross, J. C., \& Lambert, M. J. (2018). Psychotherapy relationships that work III. Psychotherapy, 55(4), 303-315. doi:10.1037/pst0000193

Rocco, D., Gennaro, A., Filugelli, L., Squarcina, P., \& Antonelli, E. (2019). Key factors in psychotherapy training: An analysis of trainers', trainees' and psychotherapists' points of view. Research in Psychotherapy: Psychopathology, Process and Outcome, 22(3), 369-378. doi:10.4081/ripppo. 2019.415.

Siegel, D. (2012). The developing mind. Second edition. New York, NY: Guilford Press.

Talia, A., Taubner, S., \& Miller-Bottome, M. (2019). Advances in research on attachment-related psychotherapy processes: seven teaching points for trainees and supervisors. Research in Psychotherapy: Psychopathology, Process and Outcome 22(3), 359-368. doi:10.4081/ripppo.2019.405.

Wampold, B. \& Imel, Z. E. (2015). The great psychotherapy debate. The evidence for what makes psychotherapy work. New York, NY: Routledge.

Westra, H. A., Constantino, M. J., Arkowitz, H., \& Dozois, D. J. A. (2011). Therapist differences in cognitive-behavioral psychotherapy for generalized anxiety disorder: A pilot study. Psychotherapy, 48(3), 283-292. doi:10.1037/ a0022011. 